\title{
How Can I Get COVID?: Understanding Differences in American Heterosexual and Sexual Minority Men's Risk Perception
}

\author{
Devon M. Price ${ }^{1}$ (1) - Amanda N. Gesselman ${ }^{2} \cdot$ Rachel A. Fikslin $^{1,3} \cdot$ Alison J. Goldberg $^{1,3} \cdot$ Omaima Pervez $^{1}$. \\ Mora A. Reinka ${ }^{4}$ Elissia Franklin ${ }^{5,6}$
}

Received: 20 December 2020 / Revised: 9 July 2021 / Accepted: 1 August 2021 / Published online: 15 November 2021

(c) The Author(s), under exclusive licence to Springer Science+Business Media, LLC, part of Springer Nature 2021

\begin{abstract}
Men are more vulnerable to COVID-19 infections compared to women, but their risk perceptions around COVID-19 are persistently lower. Further, men often engage in less health promotion behavior because self-care in this capacity is seen as weak or less masculine. This combination has consequences for mortality; thus, a better understanding of men's COVID-19 cognitions and individual difference factors is critical. In a web-based survey conducted during the beginning stages of the pandemic in the U.S., we collected risk perceptions of various sexual and non-sexual behaviors from heterosexual $(n=137)$ and gay/bisexual men $(n=108)$. There were no significant sexual orientation differences for perceptions of COVID-19 risk from routine activities or in overall risk estimates. However, gay/bisexual men did report engaging in more precautionary behavior while socializing (i.e., masking, social distancing) and reported higher risk perceptions than did heterosexual men for nearly all intimate and sexual activities. A more nuanced understanding of cognitions around COVID-19 is needed to better understand motivation for-and especially motivation against—pursuing vaccinations and continuing precautionary behavior.
\end{abstract}

Keywords Behavior change $\cdot$ COVID-19 $\cdot$ Risk perception $\cdot$ Behavioral health $\cdot$ Sexuality

\section{Introduction}

The novel coronavirus, first detected in December 2019 and appropriately named COVID-19, progressed to the level of a global pandemic in a matter of months (Cucinotta \& Vanelli, 2020). Since the initial case of COVID-19 was identified in the USA in March 2020, COVID-19 spread rapidly to all 50 states, reaching 8,249,011 confirmed cases and resulting in over 594,000 deaths by May 2021 (Centers for Disease Control \&

Devon M. Price

devonprice49@gmail.com

1 Department of Psychology, Hunter College of the City University of New York, New York, NY 10065, USA

2 The Kinsey Institute, Indiana University, Bloomington, IN, USA

3 Department of Psychology, Graduate Center of the City, University of New York, New York, NY, USA

4 Department of Psychology, Ursinus College, Collegeville, PA, USA

5 Research Her, LLC, South Holland, IL, USA

6 Purdue University, West Lafayette, IN, USA
Prevention, 2020). Although initial stay-at-home orders successfully reduced the trajectory of the contagion, these orders were lifted nationally within about a month of implementation, with individual states mandating differing precautions (CNBC, 2020). As states continued to systematically lift their individualized regulations well before the development and widespread access to a vaccine, there was a resurgence in COVID-19 cases that inevitably led to thousands of deaths in the winter of 2021 (Mallapaty, 2020).

Before COVID-19 vaccines were available in the USA, the most successful strategy for "flattening the curve" (i.e., decreasing the number of new infections) was the widespread implementation of what is, at its essence, a national behavioral change intervention: social distancing and masking (Andersen, 2020; Feng et al., 2020; Pearce, 2020; Sen-Crowe et al., 2020). Although the fundamental tenants of a successful behavioral change intervention are well known in the literature (Ajzen, 1991; Ajzen \& Madden, 1986), many of these strategies were disregarded by leadership during the ever-developing pandemic. Additionally, the USA has uniquely suffered from the politicization, and thus polarization, of these life-saving measures more than every other high-resourced country (Grossman et al., 2020). Consequently, polling data during the first few months 
of the pandemic found that nearly 1 in 5 Americans actively opposed the idea of quarantine regulations, including closing nonessential businesses, wearing masks in public spaces, and maintaining 6 feet of distance between people (Lammers et al., 2020). As the economic pressures mounted in relation to unchecked infection rates, both political parties began to call for mask adherence; however, misinformation and concerns of civil liberty infringement still abounded and have continued to proliferate into the present (McKelvey, 2020; Pew Research Center, 2020). Thus, a better understanding of group differences in COVID-19 risk perceptions and subsequent preventative behavior is critical to future COVID-19 interventions, including COVID-19 vaccination efforts.

Interventions designed to increase health promoting behaviors, such as medical or nutritional adherence in patients with diabetes (Ferrari et al., 2021), often create positive change via enhancing three domains for participants (motivation, intentions, and behavioral skills). These interventions are founded on models that have been robustly supported, including Fisher's intention, motivation, and behavioral skills model (IMB; Chang et al., 2014; Fisher \& Fisher, 2002; Zarani et al., 2010). These models call for a skill-building component to promote behavioral change, and health campaigns for COVID-19 prevention have largely centered on this aspect of implementation. For instance, the Centers for Disease Control and other American health organizations' primary messaging campaigns were about how to properly wear a mask (Centers for Disease Control, 2021). However, the aspects of these models that are often antecedents to behavioral skill development (intentions and motivations) have remained underused in the pandemic response.

Cognitive factors that influence health behavior, such as behavioral intentions and motivation, heavily contribute to one's willingness to undertake precautionary behaviors (Fisher et al., 2006; Lippke \& Ziegelmann, 2008; Rosenstock, 1974). Little attention has been paid to how the pandemic may impact cognitions surrounding other common behaviors that convey COVID-19 risk, such as sexual activity. Sexual behavior and sexual relationships with others are demonstrably linked to mental and physical well-being, and a number of theoretical models center them as critical to successful development (e.g., McCormick, Kuo, \& Masten, 2011). As in most other areas of life, the COVID-19 pandemic affected people's sexual lives as the uncertainty and disruption to daily life persisted. In fact, a recent study reported that $44 \%$ of US adults in the sample reported that the quality of their sex life had declined during the pandemic (Lehmiller et al., 2020). Even so, participants in this study reported having sex several times per month on average. Similarly, another recent study conducted during the pandemic with UK-dwelling adults reported that around $40 \%$ of their sample engaged in sexual activity at least once per week (Jacob et al., 2020). Taken together, these results demonstrate continued sexual behavior during the COVID-19 pandemic and suggest that social distancing recommendations could likely not compete with the drive for sexual need fulfillment. Understanding cognitions around risk of infection and transmission within sexual and intimate activities is critical for illustrating a clearer picture of how growing "pandemic fatigue" (e.g., becoming tired of abiding by regulations and returning to "normal" behavior; Bosman, Mervosh, \& Santora, 2020) may lead to increases in vulnerability to COVID infection. Understanding these cognitions are particularly important as vaccination rates disproportionately rise in more liberal-leaning states while conservative-leaning states have suffered a spike in cases with the more infectious COVID-19 Delta variant (Kuzmina et al, 2021).

Just as there are group differences in preventative health behaviors for other infectious diseases (Price et al., 2020; Tabaac et al., 2018; Teo et al., 2016), there are likely group differences in the ways individuals perceive the risk of COVID-19 transmission behavior due to a combination of socialization and access to resources. Notably, men appear to be especially vulnerable to COVID-19 infection. They are more likely to experience severe COVID-19 outcomes and have a higher rate of COVID19-related mortality than do women (Jin et al., 2020; Spagnolo et al., 2020; Walter \& McGregor, 2020). However, men also report less fear of COVID-19 infection than women and perceive themselves at less risk than women (Dryhurst et al., 2020; Gerhold, 2020). This combination could be dangerous and may influence their engagement in activities with others, including sexual behavior. As such, in the current study, we focus specifically on men's COVID-19-related perceptions and behaviors.

Sexual orientation is likely an additional factor in differing risk perceptions of COVID-19, especially with regard to sexual behavior. There is evidence to suggest that gay and bisexual men may have a different way of viewing sex as a COVID-19 transmission risk behavior than heterosexual men (Price et al., 2020). Men who have sex with men have consistently been the target audience for campaigns emphasizing sexual behavior as a vessel for spreading life-threatening infection, namely HIV (Nathan, 2019; Siegel \& Meunier, 2019). Previous work examining HIV risk perceptions in men of various sexual orientations indicates that heterosexual men view their risk of HIV during sexual intercourse as fundamentally different than non-heterosexual men despite both engaging in condomless sex in the past three months (Bowleg, 2004; Bowleg et al., 2011; Price et al., 2020). That is, heterosexual men perceived their risk for HIV as significantly less possible than men who were having sex with other men, despite engaging in the same transmission behavior. Recent work investigating the intersection of HIV transmission risk and COVID-19 reported that of 518 gay, bisexual, and other men who have sex with men (GBMSM), two-thirds of participants indicated they believed it possible to contract COVID-19 through sex. However, they had also gained about two more sexual partners on average during the pandemic, with anal sex being viewed as the least likely sexual method of transmission (compared to kissing, hugging, and oral sex; Stephenson et al., 
2020b). Further, a recent study of 696 GBMSM indicated that many perceived HIV as agreater risk than COVID-19, but this was dependent on participant age and their local environment (Stephenson et al., 2020b). Participants over the age of 25 and those who perceived higher prevalence of COVID-19 in their local area demonstrated the reverse effect: they perceived COVID-19 as a greater personal risk than HIV. As prevention strategies evolve (e.g., vaccinations are increasingly available at the same time more infectious variants mutate) and efforts to engage the public in preventative behavior continue, understanding reliable differences in COVID-19 cognitions will make a valuable impact on the efficacy of those strategies.

Thus far, no research has identified how heterosexual men view the risks of sexual behaviors during the COVID-19 pandemic. In the current study, we compare a sample of US-residing heterosexual men with gay and bisexual men on their perceptions of transmission risk for various intimate and sexual activities involving another person, as well as their actual partnered sexual behavior during the pandemic. Due to the prior effects mentioned, we control for age and local lockdown regulations as a proxy for risk and to understand the unique role of sexual orientation. We also control for relationship status, as those in romantic relationships tend to have sex more frequently than singles and tend to have sex with the same person (Ueda, Mercer, \& Ghaznavi, 2020), thus reducing their risk of exposure.

The present study was guided by four research questions:

RQ1: Do gay and bisexual men and heterosexual men differentially perceive their risk for COVID-19?

RQ2: Are gay and bisexual men and heterosexual men differentially taking precautions to protect themselves and others from COVID-19?
RQ3: Do gay and bisexual men and heterosexual men differentially perceive riskiness of intimate and sexual behaviors for COVID-19 transmission? And.

RQ4: Are gay and bisexual men and heterosexual men differentially engaging in sex outside of their "lockdown pods" (i.e., their home and whomever they are participating in stayat-home behaviors with) since the onset of COVID-19?

\section{Method}

\section{Participants}

Participants were 245 men: 137 (56\%) identified as heterosexual, and $108(44 \%)$ identified as gay or bisexual. Demographics are provided in Table 1.

\section{Procedure}

Participants were recruited via social media posts by [blinded for review] advertising the study and via an email list from the first author's prior studies on sexual health containing participants who had consented to be contacted again for future research purposes. Eligibility criteria were being 18 years or older, being fluent in English, and living in the USA.

The survey was conducted fully online using the RedCap platform and was self-paced. Participants could skip any items they did not wish to answer, which is reflected in fluctuating degrees of freedom in the analyses. Compensation was given in the form of 17 raffled virtual gift cards for \$40 USD ( 1 in 15 odds). Data collection occurred from April 2020-June 2020.
Table 1 Participant demographics by sexual orientation

\begin{tabular}{lll}
\hline & Participant sexual orientation & \\
\cline { 2 - 3 } & Gay or bisexual $N=108$ & Heterosexual $N=137$ \\
& $M(S D)$ & $M(S D)$ \\
\hline Age & $33.94(11.84)$ & $24.15(7.93)$ \\
Race/ethnicity & $\%(n)$ & $\%(n)$ \\
White & $69 \%(75)$ & $76 \%(104)$ \\
Black/African-American & $9 \%(10)$ & $10 \%(13)$ \\
Asian & $5 \%(5)$ & $4 \%(6)$ \\
Native Hawaiian/Pacific Islander & $1 \%(1)$ & $3 \%(4)$ \\
Native American/Alaskan Native & $1 \%(1)$ & $2 \%(2)$ \\
Multiracial & $10 \%(11)$ & $6 \%(8)$ \\
Other & $7 \%(7)$ & $6 \%(8)$ \\
Relationship status & & $66 \%(91)$ \\
Single & $57 \%(62)$ & $32 \%(44)$ \\
In a relationship & $37 \%(40)$ & $2 \%(2)$ \\
Other & $6 \%(6)$ & $1 \%(1)$ \\
Have been diagnosed with COVID-19 & $6 \%(6)$ &
\end{tabular}




\section{Measures}

These data were taken from a larger survey on multifaceted health outcomes during the COVID-19 pandemic in the USA. The purpose of the larger study was to examine individuals' risk perception and prevention behaviors, sexual health and health care access, and mental health during the COVID-19 pandemic. Here we only include measures relevant to the current study.

\section{Demographics}

Participants reported their gender, age, sexual orientation, race or ethnicity, and relationship status.

\section{COVID-19 items}

Local Lockdown Status Participants reported on the degree of "lockdown" in their local area, by checking all that applied from the following list of six items or by selecting "There are no restrictions that I'm aware of": (1) Large public gatherings have been banned or are limited in size; (2) nonessential travel has been banned or discouraged; (3) nonessential businesses are closed, including bars, restaurants, or other social gathering spots; (4) citizens have been asked to work from home whenever possible; (5) social distancing has been ordered by the government; and (6) social distancing has been enforced by the local police. This item was summed such that participants received a score based on the number of items they had checked, with "there are no restrictions that I'm aware of" receiving a zero.

Perceived Personal Risk Participants reported on their own likelihood of contracting COVID-19 in eight scenarios: within the next two weeks, within the next month, before a vaccine is available, from an asymptomatic person, from someone who had COVID-19 but recovered, from a trip to the grocery store, a trip to the pharmacy, and while going on a walk or run outside. Responses were made on a slider from $0 \%$ likely to $100 \%$ likely.

Precautionary Behaviors Participants responded to three items assessing their social distancing behavior: (1) How much would you say you're following social distancing guidelines related to COVID-19 Coronavirus?; (2) Compared to other people you know, would you say that you began to engage in social distancing early on in this pandemic or later?; and (3) How likely are you to continue to follow lockdown and social distancing orders for the duration of the pandemic, even if it lasts for months? Responses were all made on 7-point Likert-type scales $(1=$ not at all, earlier, very unlikely; $7=$ strictly, later, very likely). Note that items 2 and 3 had an additional option of "Not applicable-I'm not engaging in social distancing." For analytical purposes, these were recoded as missing data.

Participants reported whether they had been engaging in social activities with anyone outside of their lockdown pod (yes/no), and if so, how frequently $(1=$ everyday, $2=4-5$ days a week, 3 =3-4 days a week, $4=1-2$ days a week). They also reported on whether they wear masks or keep six feet apart during these activities (yes/no).

Perceived Risk from Intimate Behaviors We presented participants with the stem, "How likely is it that someone like you would get COVID-19 from..." and five intimate/sexual acts: kissing, hugging, oral sex, vaginal sex, and anal sex. Responses were made on a slider from $0 \%$ likely to $100 \%$ likely.

\section{Sexual Dehavior During the Pandemic}

Participants reported whether they had engaged in any partnered sexual activity since the beginning of the COVID-19 pandemic in the USA (since March 2020), within the last two weeks, or whether they plan to do so in the next two weeks (all yes/no). They reported how many different sexual partners they'd had in the last three months and how many times they had done each of the following within the last 30 days: given oral sex, received oral sex, had anal sex, and had vaginal sex. Last, they reported whether they had been practicing any of the following four precautions with regard to sex since the pandemic began: (1) only seeing their sex partners every two weeks after symptoms have not appeared; (2) only having sex with partners who had a negative COVID-19 test result; (3) negotiating with their partners regarding who they are exposed to; and (4) practicing abstinence (all yes/no).

\section{Analysis Plan}

We conducted linear and binary logistic regression analyses to answer our research questions. Outcome variables included perceived risk of contracting COVID-19, perceptions of COVID19 risk from various sexual and non-sexual behaviors, and perceptions of partner risk. Sexual orientation (heterosexual $=-0.5$, gay/bisexual $=0.5$ ) was the predictor variable of interest. We also included age (mean-centered), summed local lockdown status (mean-centered), and relationship status (single $=-0.5$, in a relationship $=0.5$ ) to control for their potential effects. In tests of the perceived risk of transmission from oral, anal, or vaginal sex, we included the relevant item assessing how many times they had engaged in that form of sex in the last 30 days. For oral sex, we included both variables for giving and receiving oral sex in the last 30 days.

\section{Results}

\section{RQ1: Do Gay and Bisexual Men and Heterosexual Men Differentially Perceive Their Risk for COVID-19?}

We assessed perceptions of one's own risk of contracting COVID-19 over the next two weeks, within the next month, and before a vaccine is available. There were no differences by sexual orientation in these perceptions ( $p s \geq 0.38$ ). We also 
assessed perceptions of one's own risk of contracting COVID19 from an asymptomatic person, someone who had COVID-19 but recovered, and from outings, including trips to the grocery store, pharmacy, and going for a run or walk outside. There were no differences by sexual orientation in any of these perceptions (all $p s \geq 0.15$ ). See Table 2 .

\section{RQ2: Are Gay and Bisexual Men and Heterosexual Men Differentially Taking Precautions to Protect Themselves and Others From COVID-19?}

We assessed strictness of social distancing behavior, earliness of social distancing onset, and intention to continue social distancing over the coming months. There were no differences by sexual orientation (all $p \mathrm{~s} \geq 0.29$ ). We also assessed whether participants were socializing outside of their "lockdown pod," and, if so, the frequency with which they were socializing outside their pod as well as the precautions taken: keeping 6 feet apart and wearing masks. Gay and bisexual men were more likely to have been socializing outside of their pod at nearly twice the rate of heterosexual men $(\mathrm{OR}=1.93,95 \% \mathrm{CI}[1.00,3.71])$. However, when comparing among those who reported socializing outside of their pod, there were no sexual orientation differences in the frequency of this socialization $(p=0.15)$. Last, during their socializing, gay and bisexual men were over twice as likely as heterosexual men to report taking CDC-recommended precautions: wearing masks $(\mathrm{OR}=2.69,95 \% \mathrm{CI}[1.11,6.50])$ and staying 6 feet apart $(\mathrm{OR}=2.29,95 \% \mathrm{CI}[1.07,4.93])$. See Table 3 and 4 for all regression coefficients.

\section{RQ3: Do Gay and Bisexual Men and Heterosexual Men Differentially Perceive Riskiness of Intimate and Sexual Behaviors for COVID-19 Transmission?}

We assessed perceptions of COVID-19 transmission risk from kissing, hugging, oral sex, anal sex, and vaginal sex. Gay and bisexual men perceived greater risk than did heterosexual men for hugging, kissing, oral sex, and anal sex, even when controlling for their engagement in these behaviors in the last 30 days. However, there were no sexual orientation differences for perceptions of vaginal sex transmission. See Table 5 for descriptive and inferential statistics.

\section{RQ4: Are Gay and Bisexual Men and Heterosexual Men Differentially Engaging in Sex Outside of Their Lockdown Pods Since the Onset of COVID-19?}

We assessed whether participants had engaged in sexual behavior since the onset of COVID-19, in the last two weeks, or intend to have sex in the next two weeks; how many different partners they had had in the last three months; whether they reported having sex with someone outside of their lockdown pod; and whether they were taking more precautions to prevent COVID19 transmissions with their sexual partners. There were no sexual orientation differences in reports of sex since the onset of COVID-19, sex in the last two weeks, intentions to have sex in the next two weeks, having sex outside of their lockdown pod, or in taking new precautions with sex partners. However, gay and bisexual men reported having more sexual partners in the last three months than did heterosexual men $(p<0.001$; $M_{\text {gay } / \text { isexual }}=3.99, S D=5.32 ; M_{\text {heterosexual }}=0.84, S D=0.70$ ). See Tables 6 and 7.

\section{Discussion}

In the current study, we assessed overall risk perceptions related to COVID-19, as well as perceptions of the risk inherent in routine activities (e.g., going to the grocery store) and social behavior (e.g., socializing with friends outside of one's "lockdown pod") of heterosexual and gay and bisexual men in the USA. Key to our investigation, we also assessed risk perceptions of various intimate and sexual behaviors (e.g., kissing, oral sex), and conducted our investigation with heterosexual versus gay and bisexual men. We focused on group differences within men due to their heightened vulnerability to COVID-19 compared to women (Jin et al., 2020; Spagnolo et al., 2020; Walter \& McGregor, 2020) and existing data on reduced rates of COVID-19 prevention behavior among men (Dryhurst et al., 2020; Gerhold, 2020). Further, our focus on sexual orientation comparisons, specifically of gay and bisexual men compared to heterosexual men, was informed by the literature on differential cognitions around HIV among these groups. Heterosexual men have consistently reported their risk for HIV as lower than gay or bisexual men, even when engaging in HIV transmission behavior themselves (i.e., condomless sex with more than one partner) (Bowleg, 2004; Bowleg et al., 2011; Price et al., 2020). HIV awareness campaigns have focused overwhelmingly on messaging around sex as a transmission tool for contagion, and gay and bisexual men have been the predominantly targeted audience (Nathan, 2019; Siegel \& Meunier, 2019). It follows that heterosexual men would perceive their risk as lower or nonexistent in comparison. For COVID-19 transmission, partnered sex is a clear concern (ASHM, 2020). Thus, we investigated perceptions of COVID-19 transmission risk across various intimate and sexual behaviors. This allowed for observing whether the work conducted in HIV intervention has potential transfer effects, rendering gay and bisexual men more perceptive of the risks inherent in partnered sexual behavior during the pandemic.

Our findings illustrate several important differences in the ways in which gay and bisexual men and heterosexual men perceive their risk of COVID-19 in relation to sex and their subsequent preventative behaviors. First, there were no differences found between the groups in terms of general perceptions of risk 
Table 2 Linear regression coefficients for the association between sexual orientation and COVID-19 risk perceptions of routine behaviors

\begin{tabular}{|c|c|c|c|c|c|c|c|c|c|c|}
\hline & \multicolumn{5}{|c|}{ Model 1: Within next 2 weeks } & \multicolumn{5}{|c|}{ Model 2: Within next month } \\
\hline & \multirow[t]{2}{*}{$b$} & \multirow[t]{2}{*}{$S E$} & \multicolumn{2}{|l|}{$95 \% \mathrm{CI}$} & \multirow[t]{2}{*}{$p$} & \multirow[t]{2}{*}{$b$} & \multirow[t]{2}{*}{$S E$} & \multicolumn{2}{|l|}{$95 \% \mathrm{CI}$} & \multirow[t]{2}{*}{$p$} \\
\hline & & & LL & UL & & & & UL & LL & \\
\hline Sexual orientation & 2.27 & 3.12 & -3.87 & 8.42 & .466 & 1.62 & 3.75 & -5.79 & 9.02 & .667 \\
\hline \multicolumn{11}{|l|}{ Covariates } \\
\hline Age & -0.06 & 0.15 & -0.36 & 0.25 & .714 & -0.20 & 0.19 & -0.57 & 0.17 & .279 \\
\hline Local lockdown status & 1.75 & 1.08 & -0.38 & 3.87 & .107 & 1.63 & 1.30 & -0.93 & 4.19 & .210 \\
\hline \multirow[t]{2}{*}{ Relationship status } & -3.26 & 3.19 & -9.54 & 3.03 & .308 & -3.28 & 3.87 & -10.91 & 4.36 & .399 \\
\hline & $M$ & $S D$ & & & & $M$ & $S D$ & & & \\
\hline Heterosexual men & 21.69 & 20.27 & & & & 30.91 & 23.93 & & & \\
\hline \multirow[t]{4}{*}{ Gay/bisexual men } & 23.97 & 19.33 & & & & 30.42 & 23.77 & & & \\
\hline & \multicolumn{4}{|c|}{ Model 3: Before a vaccine is available } & & \multicolumn{5}{|c|}{ Model 4: From an asymptomatic person } \\
\hline & \multirow[t]{2}{*}{$b$} & \multirow[t]{2}{*}{$S E$} & \multicolumn{2}{|l|}{$95 \% \mathrm{CI}$} & \multirow[t]{2}{*}{$p$} & \multirow[t]{2}{*}{$b$} & \multirow[t]{2}{*}{$S E$} & \multicolumn{2}{|l|}{$95 \% \mathrm{CI}$} & $p$ \\
\hline & & & LL & UL & & & & UL & LL & \\
\hline Sexual orientation & 4.10 & 4.67 & -5.10 & 13.30 & .381 & 5.80 & 4.01 & -2.11 & 13.72 & .150 \\
\hline Covariates & & & & & & & & & & \\
\hline Age & -0.06 & 0.23 & -0.51 & 0.40 & .808 & -0.13 & 0.19 & -0.51 & 0.24 & .485 \\
\hline Local lockdown status & 2.95 & 1.65 & -0.30 & 6.21 & .075 & 2.70 & 1.39 & -0.05 & 5.44 & .054 \\
\hline Relationship status & -0.52 & 4.76 & -9.91 & 8.86 & .912 & 4.18 & 4.07 & -3.84 & 12.20 & .305 \\
\hline & $M$ & $S D$ & & & & $M$ & $S D$ & & & \\
\hline Heterosexual men & 46.86 & 29.51 & & & & 46.12 & 27.31 & & & \\
\hline Gay/bisexual men & 51.56 & 29.86 & & & & 52.95 & 24.63 & & & \\
\hline & Model & $m$ a per & ho has re & & & Model & $\mathrm{m}$ a trip & e grocery & & \\
\hline & $b$ & $S E$ & $95 \% \mathrm{CI}$ & & $p$ & $b$ & $S E$ & $95 \% \mathrm{CI}$ & & $p$ \\
\hline & & & UL & LL & & & & LL & UL & \\
\hline Sexual orientation & 4.89 & 3.83 & -2.67 & 12.44 & .204 & 4.45 & 3.89 & -3.21 & 12.12 & .253 \\
\hline Covariates & & & & & & & & & & \\
\hline Age & -0.36 & 0.18 & -0.72 & -0.00 & .048 & -0.33 & 0.19 & -0.70 & 0.03 & .073 \\
\hline Local lockdown status & -0.45 & 1.32 & -3.06 & 2.15 & .731 & 0.08 & 1.35 & -2.58 & 2.74 & .955 \\
\hline Relationship status & -1.92 & 3.85 & -9.51 & 5.67 & .619 & 4.76 & 3.93 & -2.99 & 12.51 & .227 \\
\hline & $M$ & $S D$ & & & & & & & & \\
\hline Heterosexual men & 31.35 & 24.36 & & & 43.77 & 25.87 & & & & \\
\hline Gay/bisexual men & 31.37 & 24.72 & & & 44.92 & 24.06 & & & & \\
\hline & Model & $\mathrm{m}$ a trip & e pharma & & & Model & om a wa & run outsid & & \\
\hline & $b$ & $S E$ & $95 \% \mathrm{CI}$ & & $p$ & $b$ & $S E$ & $95 \% \mathrm{CI}$ & & $p$ \\
\hline & & & $\mathrm{UL}$ & LL & & & & LL & $\mathrm{UL}$ & \\
\hline Sexual orientation & 2.72 & 4.06 & -5.28 & 10.72 & .504 & 2.98 & 3.16 & -3.26 & 9.22 & .348 \\
\hline Covariates & & & & & & & & & & \\
\hline Age & -0.51 & 0.19 & -0.88 & -0.13 & .009 & -0.26 & 0.15 & -0.55 & 0.04 & .093 \\
\hline Local lockdown status & -1.94 & 1.40 & -0.81 & 4.70 & .165 & 0.23 & 1.10 & -1.94 & 2.39 & .835 \\
\hline Relationship status & -5.08 & 4.07 & -2.94 & 13.11 & .213 & -0.82 & 3.20 & -7.12 & 5.52 & .803 \\
\hline & $M$ & $S D$ & & & & $M$ & $S D$ & & & \\
\hline Heterosexual men & 41.82 & 24.36 & & & & 21.63 & 20.04 & & & \\
\hline Gay/bisexual men & 40.98 & 24.8 & & & & 22.91 & 20.83 & & & \\
\hline
\end{tabular}

Model 1: $R^{2}=0.02, R^{2}$ adjusted $=0.003, F(4,190)=1.12, p=.347$; Model $2: R^{2}=0.02, R^{2}$ adjusted $=0.001, F(4,188)=1.04, p<.388$. $b=$ unstandardized regression coefficient, $S E$ standard error, CI confidence interval, $L L$ lower limit, $U L$ upper limit, $p=p$ value, $M$ mean, $S D=$ standard deviation Model 3: $R^{2}=0.10, R^{2}$ adjusted $=0.02, F(4,192)=1.14, p=.340$; Model 4: $R^{2}=0.04, R^{2}$ adjusted $=0.02, F(4$, 194) $=1.99, p=.097$; Model 5: $R^{2}=0.03, R^{2}$ adjusted $=0.01, F(4,192)=1.39, p=.239 . b=$ unstandardized regression coefficient, $S E$ standard error, $C I$ confidence interval, $L L$ lower limit, $U L$ upper limit, $p=p$ value, $M$ mean, $S D$ standard deviation. Model 6: $R^{2}=0.02, R^{2}$ adjusted $=0.001, F(4,195)=1.04, p=.388 ;$ Model 7: $R^{2}=0.05, R^{2}$ adjusted $=0.04, F(4,191)=2.32, p=.058 ;$ Model $8: R^{2}=0.02, R^{2}$ 
Table 2 (continued)

adjusted $=-0.002, F(4,195)=0.89, p=.474 . b=$ unstandardized regression coefficient, $S E=$ standard error, $C I$ confidence interval, $L L$ lower limit, $U L$ upper limit, $p=p$ value, $M$ mean, $S D$ standard deviation.

Table 3 Linear regression coefficients for the association between sexual orientation and reports of social distancing and socializing outside of one's lockdown pod

\begin{tabular}{|c|c|c|c|c|c|c|c|c|c|c|}
\hline & \multicolumn{5}{|c|}{ Model 1: Following social distancing guidelines } & \multicolumn{5}{|c|}{ Model 2: How soon they began social distancing } \\
\hline & \multirow[t]{2}{*}{$b$} & \multirow[t]{2}{*}{$S E$} & \multicolumn{2}{|l|}{$95 \% \mathrm{CI}$} & \multirow[t]{2}{*}{$p$} & \multirow[t]{2}{*}{$b$} & \multirow[t]{2}{*}{$S E$} & \multicolumn{2}{|l|}{$95 \% \mathrm{CI}$} & \multirow[t]{2}{*}{$p$} \\
\hline & & & $\mathrm{UL}$ & LL & & & & $\mathrm{UL}$ & LL & \\
\hline Sexual orientation & 0.16 & 0.15 & -0.14 & 0.47 & .286 & -0.18 & 0.23 & -0.63 & 0.28 & .444 \\
\hline \multicolumn{11}{|l|}{ Covariates } \\
\hline Age & 0.02 & 0.01 & 0.00 & 0.03 & .025 & -0.01 & 0.01 & -0.03 & -0.01 & .432 \\
\hline Local lockdown status & 0.16 & 0.05 & 0.06 & 0.27 & .002 & -0.16 & 0.08 & -0.32 & -0.00 & .045 \\
\hline \multirow[t]{2}{*}{ Relationship status } & 0.13 & 0.15 & -0.17 & 0.43 & .389 & -0.41 & 0.23 & -0.87 & 0.05 & .080 \\
\hline & $M$ & $S D$ & & & & $M$ & $S D$ & & & \\
\hline Heterosexual men & 5.39 & 1.12 & & & & 2.96 & 1.61 & & & \\
\hline \multirow[t]{4}{*}{ Gay/bisexual men } & 5.75 & 1.04 & & & & 2.62 & 1.47 & & & \\
\hline & \multicolumn{5}{|c|}{ Model 3: Intentions to continue social distancing } & \multicolumn{5}{|c|}{ Model 4: Frequency of socializing outside lockdown pod } \\
\hline & \multirow[t]{2}{*}{$b$} & \multirow[t]{2}{*}{$S E$} & \multicolumn{2}{|l|}{$95 \% \mathrm{CI}$} & \multirow[t]{2}{*}{$p$} & \multirow[t]{2}{*}{$b$} & \multirow[t]{2}{*}{$S E$} & \multirow{2}{*}{$\begin{array}{l}95 \% \text { CI } \\
\text { UL }\end{array}$} & \multirow{2}{*}{$\begin{array}{l}p \\
\text { LL }\end{array}$} & \multirow[t]{2}{*}{$b$} \\
\hline & & & UL & LL & & & & & & \\
\hline Sexual orientation & 0.14 & 0.22 & -0.29 & 0.57 & .510 & -0.25 & 0.17 & -0.59 & 0.09 & .145 \\
\hline \multicolumn{11}{|l|}{ Covariates: } \\
\hline Age & 0.01 & 0.01 & -0.02 & 0.03 & .583 & 0.00 & 0.01 & -0.01 & 0.02 & .888 \\
\hline Local lockdown status & 0.12 & 0.08 & -0.03 & 0.27 & .110 & 0.06 & 0.06 & -0.06 & 0.18 & .343 \\
\hline \multirow[t]{2}{*}{ Relationship status } & 0.42 & 0.22 & -0.01 & 0.85 & .058 & 0.18 & 0.17 & -0.16 & 0.51 & .291 \\
\hline & $M$ & $S D$ & & & & $M$ & $S D$ & & & \\
\hline Heterosexual men & 5.63 & 1.58 & & & & 3.86 & 0.35 & & & \\
\hline Gay/bisexual men & 5.90 & 1.28 & & & & 3.70 & 0.72 & & & \\
\hline
\end{tabular}

Model 1: $R^{2}=0.11, R^{2}$ adjusted $=0.09, F(4,210)=6.26, p<.001$; Model $2: R^{2}=0.06, R^{2}$ adjusted $=0.04, F(4,208)=3.15, p=.015 ; b=$ unstandardized regression coefficient, $S E$ standard error, $C I$ confidence interval, $L L$ lower limit, $U L$ upper limit, $p=p$ value, $M$ mean, $S D$ standard deviation

Model 3: $R^{2}=0.05, R^{2}$ adjusted $=0.03, F(4,210)=2.54, p=.041$; Model 4: $R^{2}=0.06, R^{2}$ adjusted $=0.00, F(4,60)=1.00, p=.413 ; b$ unstandardized regression coefficient, $S E$ standard error, $C I$ confidence interval, $L L$ lower limit, $U L$ upper limit, $p=p$ value, $M$ mean, $S D$ standard deviation.

Table 4 Logistic regression coefficients for models using sexual orientation as a predictor of socialization outside of one's lockdown pod and related precautions

\begin{tabular}{llll}
\hline & \multicolumn{2}{l}{ Social precautions because of COVID-19 } \\
\cline { 2 - 4 } & $\begin{array}{l}\text { Socializing outside of pod } \\
\text { OR }[95 \% \mathrm{CI}]\end{array}$ & $\begin{array}{l}\text { Wearing masks } \\
\text { OR }[95 \% \mathrm{CI}]\end{array}$ & $\begin{array}{l}\text { Keeping 6 feet apart } \\
\text { OR [95\% CI] }\end{array}$ \\
\hline Sexual orientation & $1.93[1.00,3.71]$ & $2.69[1.11,6.50]$ & $2.29[1.07,4.93]$ \\
Covariates & & & \\
Age & $1.01[0.98,1.04]$ & $1.00[0.96,1.04]$ & $1.00[0.97,1.04]$ \\
Local lockdown status & $1.01[0.80,1.27]$ & $1.27[0.97,1.67]$ & $1.30[1.02,1.65]$ \\
Relationship status & $0.81[0.42,1.58]$ & $0.54[0.22,1.32]$ & $0.80[0.38,1.71]$ \\
Descriptive statistics & $M(S D)$ & $M(S D)$ & $M(S D)$ \\
Heterosexual men & $0.25(0.44)$ & $0.09(0.28)$ & $0.12(0.33)$ \\
Gay and bisexual men & $0.40(0.49)$ & $0.19(0.40)$ & $0.26(0.44)$ \\
\hline
\end{tabular}

$O R$ odds ratio; $C I$ confidence interval, $M$ mean, $S D$ standard deviation 
Table 5 Linear regression coefficients for the association between sexual orientation and risk perceptions of intimate/sexual behaviors, controlling for demographics and recent engagement in the relevant behavior

\begin{tabular}{|c|c|c|c|c|c|}
\hline & \multicolumn{5}{|c|}{ Model 1: Hugging } \\
\hline & \multirow[t]{2}{*}{$b$} & \multirow[t]{2}{*}{$S E$} & \multicolumn{2}{|l|}{$95 \%$ CI } & \multirow[t]{2}{*}{$p$} \\
\hline & & & LL & UL & \\
\hline Sexual orientation & 11.16 & 4.68 & 1.93 & 20.38 & .02 \\
\hline \multicolumn{6}{|l|}{ Covariates } \\
\hline Age & -0.25 & 0.22 & -0.69 & 0.19 & .27 \\
\hline Local lockdown status & 3.68 & 1.61 & 0.52 & 6.85 & .02 \\
\hline \multirow[t]{2}{*}{ Relationship status } & 3.75 & 4.67 & -5.46 & 12.97 & .80 \\
\hline & $M$ & $S D$ & & & \\
\hline Heterosexual men & 40.85 & 30.30 & & & \\
\hline \multirow[t]{4}{*}{ Gay/bisexual men } & 48.27 & 27.35 & & & \\
\hline & \multicolumn{5}{|c|}{ Model 2: Kissing } \\
\hline & \multirow[t]{2}{*}{$b$} & \multirow[t]{2}{*}{$S E$} & \multicolumn{2}{|l|}{$95 \% \mathrm{CI}$} & \multirow[t]{2}{*}{$p$} \\
\hline & & & UL & LL & \\
\hline Sexual orientation & 17.30 & 5.60 & 6.26 & 28.34 & .002 \\
\hline \multicolumn{6}{|l|}{ Covariates } \\
\hline Age & -0.07 & 0.27 & -0.59 & 0.46 & .803 \\
\hline Local lockdown status & 5.69 & 1.93 & 1.88 & 9.50 & .004 \\
\hline \multirow[t]{2}{*}{ Relationship status } & 5.95 & 5.63 & -5.16 & 17.06 & .292 \\
\hline & $M$ & $S D$ & & & \\
\hline Heterosexual men & 43.48 & 36.59 & & & \\
\hline \multirow[t]{4}{*}{ Gay/bisexual men } & 53.98 & 38.12 & & & \\
\hline & \multicolumn{5}{|c|}{ Model 3: Oral sex } \\
\hline & \multirow[t]{2}{*}{$b$} & \multirow[t]{2}{*}{$S E$} & \multicolumn{2}{|l|}{$95 \%$ CI } & \multirow[t]{2}{*}{$p$} \\
\hline & & & UL & LL & \\
\hline Sexual orientation & 19.94 & 5.68 & 8.74 & 31.14 & .001 \\
\hline \multicolumn{6}{|l|}{ Covariates } \\
\hline Age & -0.13 & 0.27 & -0.66 & 0.39 & .620 \\
\hline Local lockdown status & 3.80 & 1.90 & 0.50 & 7.56 & .047 \\
\hline Relationship status & -1.79 & 5.84 & -13.31 & 9.73 & .759 \\
\hline Times given oral sex & -1.82 & 1.42 & -4.62 & 0.99 & .202 \\
\hline Times rec'd oral sex & 0.92 & 1.37 & -1.78 & 3.63 & .502 \\
\hline \multicolumn{6}{|l|}{ Times had anal sex } \\
\hline \multicolumn{6}{|l|}{ Times had vaginal sex } \\
\hline & $M$ & $S D$ & & & \\
\hline Heterosexual men & 33.62 & 32.59 & & & \\
\hline Gay/bisexual men & 42.56 & 36.57 & & & \\
\hline & Model & & & & \\
\hline & $b$ & $S E$ & $95 \% \mathrm{CI}$ & & $p$ \\
\hline & & & UL & LL & \\
\hline Sexual orientation & 25.74 & 5.83 & 14.24 & 37.24 & .000 \\
\hline Covariates & & & & & \\
\hline Age & -0.02 & 0.27 & -0.55 & 0.52 & .952 \\
\hline Local lockdown status & 3.12 & 1.92 & -0.67 & 6.92 & .106 \\
\hline Relationship status & -8.56 & 5.62 & -19.66 & 2.53 & .129 \\
\hline
\end{tabular}


Table 5 (continued)

\begin{tabular}{|c|c|c|c|c|c|}
\hline & \multicolumn{5}{|c|}{ Model 4: Anal sex } \\
\hline & \multirow[t]{2}{*}{$b$} & \multirow[t]{2}{*}{$S E$} & \multicolumn{2}{|l|}{$95 \% \mathrm{CI}$} & \multirow[t]{2}{*}{$p$} \\
\hline & & & UL & LL & \\
\hline \multicolumn{6}{|l|}{ Times given oral sex } \\
\hline \multicolumn{6}{|l|}{ Times rec'd oral sex } \\
\hline Times had anal sex & 0.05 & 0.81 & -1.56 & 1.66 & .951 \\
\hline \multicolumn{6}{|l|}{ Times had vaginal sex } \\
\hline & $M$ & $S D$ & & & \\
\hline Heterosexual men & 25.64 & 31.81 & & & \\
\hline \multirow[t]{4}{*}{ Gay/bisexual men } & 39.79 & 37.18 & & & \\
\hline & \multicolumn{5}{|c|}{ Model 5: Vaginal sex } \\
\hline & \multirow[t]{2}{*}{$b$} & \multirow[t]{2}{*}{$S E$} & \multicolumn{2}{|l|}{$95 \% \mathrm{CI}$} & \multirow[t]{2}{*}{$p$} \\
\hline & & & UL & LL & \\
\hline Sexual orientation & 7.29 & 6.14 & -4.83 & 19.42 & .237 \\
\hline \multicolumn{6}{|l|}{ Covariates } \\
\hline Age & 0.04 & 0.29 & -0.52 & 0.60 & .881 \\
\hline Local lockdown status & 2.86 & 2.04 & -1.16 & 6.88 & .162 \\
\hline Relationship status & -6.85 & 6.38 & -19.17 & 6.01 & .304 \\
\hline \multicolumn{6}{|l|}{ Times given oral sex } \\
\hline \multicolumn{6}{|l|}{ Times rec'd oral sex } \\
\hline \multicolumn{6}{|l|}{ Times had anal sex } \\
\hline \multirow[t]{2}{*}{ Times had vaginal sex } & 0.38 & 0.59 & -0.78 & 1.54 & .520 \\
\hline & $M$ & $S D$ & & & \\
\hline Heterosexual men & 32.66 & 32.22 & & & \\
\hline Gay/bisexual men & 35.26 & 37.96 & & & \\
\hline
\end{tabular}

Model 1: $R^{2}=0.07, R^{2}$ adjusted $=0.05, F(4,192)=3.37, p=.011$; Model $2: R^{2}=0.11, R^{2}$ adjusted $=0.10, F(4,195)=6.27, p<.001 . b=$ unstandardized regression coefficient, $S E$ standard error, $C I$ confidence interval, $L L$ lower limit, $U L$ upper limit, $p=p$ value, $M$ mean, $S D$ standard deviation

Model 3: $R^{2}=0.10, R^{2}$ adjusted $=0.07, F(6,180)=3.44, p=.003$; Model 4: $R^{2}=0.15, R^{2}$ adjusted $=0.13, F(5,178)=6.33, p<.001 ;$ Model 5: $R^{2}=0.03, R^{2}$ adjusted $=0.002, F(5,178)=1.06, p=.382 . b=$ unstandardized regression coefficient, $S E$ standard error, $C I$ confidence interval, $L L$ lower limit, $U L$ upper limit, $p=p$ value, $M$ mean, $S D$ standard deviation.

of COVID-19 (e.g., how likely they are to contract COVID-19 in the next two weeks, in the next month, or before a vaccine is accessible). There were also no differences in men's perceptions of risk from routine activities (e.g., going to the grocery store) or risk from social contact with another person (e.g., an asymptomatic or recovered person). However, we found significant differences in the perceptions of COVID-19 transmission risk from sexual and intimate behaviors, as well as in their self-reported social and sexual behaviors. Although there were no sexual orientation-based differences in how often men socialized outside of their pod, gay and bisexual men were more likely to be doing so at all. Within these social settings, gay and bisexual men were nearly twice as likely to wear a mask and to keep six feet apart.

Gay and bisexual men perceived greater risk of COVID-19 transmission via kissing, hugging, oral sex, and anal sex than did heterosexual men. While they perceived most partnered intimate and sexual acts to be more risky, gay and bisexual men still reported more sex partners in the past three months of the pandemic than did heterosexual men. Interestingly, gay and bisexual men did not differ from heterosexual men in their risk perceptions around vaginal sex. Comparing risk perceptions, vaginal sex was perceived as the least risky of all assessed behaviors for gay and bisexual men. Because the phrasing of our risk perception items asked participants to evaluate the risk for "someone like you," this likely reflects vaginal sex being less common among this group. We attempted to correct for this by including self-reported 30-day engagement in the relevant sexual behaviors in our statistical models. However, our data cannot account for lifetime engagement. It is also of note that most HIV transmission campaigns either make no mention of vaginal sex or give it substantially less mention than anal sex (Veronese et al., 2020; Xin et al., 2020). Thus, it is likely that vaginal sex would be perceived as less risky due to the apparent lack of concern on behalf of the public health messaging organizations. Finally, 
Table 6 Logistic regression coefficients for models using sexual orientation as a predictor of sexual behavior during the pandemic and related precautions

\begin{tabular}{|c|c|c|c|c|}
\hline & \multirow{2}{*}{$\begin{array}{l}\text { Sex during the pandemic } \\
\text { OR }[95 \% \mathrm{CI}]\end{array}$} & \multirow{2}{*}{\multicolumn{2}{|c|}{ Sex in the last 2 weeks }} & $\begin{array}{l}\text { Intentions to have sex } \\
\text { in next } 2 \text { weeks }\end{array}$ \\
\hline & & & & OR $[95 \% \mathrm{CI}]$ \\
\hline Sexual orientation & \multirow[t]{2}{*}{$0.91[0.45,1.87]$} & \multicolumn{2}{|c|}{$1.13[0.51,2.49]$} & $1.00[0.47,2.12]$ \\
\hline \multicolumn{4}{|l|}{ Covariates } & \\
\hline Age & $1.03[0.99,1.06]$ & \multicolumn{2}{|c|}{$1.02[0.99,1.06]$} & $1.02[0.99,1.06]$ \\
\hline Local lockdown status & $1.18[0.92,1.53]$ & \multicolumn{2}{|c|}{$1.20[0.88,1.64]$} & $1.20[0.90,1.59]$ \\
\hline Relationship status & $5.48[2.77,10.86]^{* * *}$ & \multicolumn{2}{|c|}{$8.41[3.99,17.75]^{* * *}$} & $7.75[3.82,15.73]^{* * *}$ \\
\hline Descriptive statistics & $M(S D)$ & \multicolumn{2}{|c|}{$M(S D)$} & $M(S D)$ \\
\hline Heterosexual men & $0.38(0.49)$ & \multicolumn{2}{|c|}{$0.24(0.43)$} & $0.31(0.46)$ \\
\hline \multirow[t]{4}{*}{ Gay and bisexual men } & $0.47(0.50)$ & \multicolumn{2}{|c|}{$0.34(0.48)$} & $0.39(0.49)$ \\
\hline & \multicolumn{4}{|l|}{ New precautionary behaviors } \\
\hline & Only visiting every 14 days & $\begin{array}{l}\text { Requiring a negative } \\
\text { COVID-19 test }\end{array}$ & $\begin{array}{l}\text { Negotiating exposure to } \\
\text { others }\end{array}$ & Practicing abstinence \\
\hline & OR $[95 \% \mathrm{CI}]$ & OR $[95 \% \mathrm{CI}]$ & OR $[95 \% \mathrm{CI}]$ & OR $[95 \% \mathrm{CI}]$ \\
\hline Sexual orientation & $0.71[0.22,2.29]$ & $1.39[0.41,4.76]$ & $2.14[0.94,4.86]$ & $1.62[0.83,3.15]$ \\
\hline \multicolumn{5}{|l|}{ Covariates } \\
\hline Age & $0.93[0.86,1.01]$ & $1.00[0.94,1.06]$ & $1.01[0.97,1.04]$ & $1.03[1.00,1.07]$ \\
\hline Local lockdown status & $1.04[0.79,1.35]$ & $1.03[0.76,1.41]$ & $1.31[1.01,1.71]^{*}$ & $1.23[1.03,1.47]^{*}$ \\
\hline Relationship status & $2.75[1.00,7.59]^{*}$ & $0.47[0.12,1.81]$ & $1.12[0.51,2.44]$ & $0.13[0.06,0.28] * * *$ \\
\hline \multicolumn{5}{|l|}{ Descriptive statistics } \\
\hline Heterosexual men & $0.09(0.29)$ & $0.06(0.24)$ & $0.09(0.29)$ & $0.27(0.45)$ \\
\hline Gay and bisexual men & $0.06(0.23)$ & $0.06(0.25)$ & $0.23(0.42)$ & $0.40(0.49)$ \\
\hline
\end{tabular}

OR odds ratio; $C I$ confidence interval; $M$ mean; $S D$ standard deviation. $* * * p<.001,{ }^{*} p<.05$

it is plausible that both groups of men-and perhaps people in general-perceive women as more likely to be healthy or take care of their health, as this fits within feminine, help-seeking,

Table 7 Linear regression coefficients for the association between sexual orientation and number of sexual partners in the last 3 months

\begin{tabular}{llllll}
\hline & \multicolumn{5}{c}{ Model 1: sexual partners in last 3 months } \\
\cline { 2 - 5 } & $b$ & $S E$ & \multicolumn{2}{c}{ 95\% CI } & \\
\cline { 3 - 5 } & & & $\mathrm{LL}$ & $\mathrm{UL}$ & \\
\hline Sexual orientation & 3.01 & 0.74 & 1.55 & 4.47 & $<.001$ \\
Covariates & & & & & \\
Age & -0.22 & 0.03 & -0.09 & 0.04 & .514 \\
Local lockdown status & 0.36 & 0.27 & -0.18 & 0.91 & .186 \\
Relationship status & -1.45 & 0.71 & -2.86 & -0.04 & .044 \\
& $M$ & $S D$ & & & \\
Heterosexual men & 0.84 & 0.70 & & & \\
Gay/bisexual men & 3.99 & 5.32 & & & \\
\hline
\end{tabular}

Model 1: $R^{2}=0.17, R^{2}$ adjusted $=0.15, F(4,128)=6.68, p<.001$. $b=$ unstandardized regression coefficient, $S E$ standard error, $C I$ confidence interval, $L L$ lower limit, $U L$ upper limit, $p=p$ value, $M$ mean, $S D$ standard deviation and caretaking gender stereotypes (Dalessandro, 2019; Liddon et al., 2018).

The observed differences in prosocial protective behaviorthat is, gay and bisexual men wearing masks and maintaining social distance when they socialize with others - may reflect differences in personal importance of outwardly displaying stereotypically masculine behavior. For instance, there is a wealth of the literature suggesting that men engage less often in preventative health behaviors than do women because being sick could be perceived as "weak" and/or less masculine by other men (Fleming et al., 2014; Levant \& Wimer, 2014). Studies examining this by sexual orientation have shown a strong pattern of differences, with gay and bisexual men being less impacted by these masculine ideals than heterosexual men (Edwards, 2012). Of course, gay and bisexual men also adhere to masculinity norms to varying degrees (Ravenhill \& de Visser, 2017). Future researchers should attempt to capture more data at the intersection of masculinity norms and social norms around community protection, as HIV messaging campaigns tend to place emphasis on protecting the LGBTQ + community at large. Being able to more thoroughly understand the motivation behind putting the "greater good" above potentially harmful gender norms would 
provide a wealth of valuable information to public health scholars working in men's health and wellness.

In terms of sexual behavior, there were no sexual orientation differences in reports of having had sex since the onset of COVID-19 or in the last two weeks; intentions to have sex in the next two weeks; having sex with someone outside of their lockdown pod; or in taking new precautions with sex partners. However, gay and bisexual men reported having on average three more sexual partners in the last three months than did heterosexual men. This finding replicates previous work on COVID-19 showing that gay and bisexual men have continued to be sexually active outside of their pod during the pandemic (Stephenson et al., 2020b). Additionally, because there was no difference in sexual frequency, but a difference in the number of partners did emerge, gay and bisexual men may be more often having sex with new partners or engaging in one-off sexual encounters. Although we cannot know from the current data, it is plausible that aspects of the pandemic may have increased sexual activity and consequently the number of sexual partners for some, as some individuals engage in sex as a method of coping with stress, social isolation, and loneliness (Nagoski, 2015). There may have also been increased opportunities for sex due to shifting schedules in the pandemic (e.g., being at home rather than at work), which lend support to the lack of differences found between sexual orientations in sexual frequency.

Relatedly, while gay and bisexual men did report more preventative social behaviors, they did not report taking more COVID-19 precautions with their sexual partners (i.e., asking partners to get COVID tested before encounters). Our data cannot provide a rationale for this, but it may reflect some prior connection to a partner before engaging in sex. Specifically, these men may have already known their sex partners (e.g., as friends) and were thus aware of how cautious that person had been in their COVID-19 behavior; they may have met their partners through their friend networks, instilling more confidence in their sexual partners as safe because they were seemingly more vetted; or they may have discussed their COVID-19 risk behaviors and infection status over dating apps before meeting in person. Dating apps have begun to facilitate these conversations for users by adding a vaccination status component to daters' profiles (Breslow, 2021).

In sum, our findings show no differences by sexual identity for general COVID-19 risk perceptions, but do show differences for risk perceptions around intimate and sexual behaviors. For most of these behaviors, gay and bisexual men reported more risk than did heterosexual men. In terms of actual behavior, gay and bisexual men were more likely to be socializing outside of their lockdown pod, but were more likely than heterosexual men to be taking steps to protect themselves and their social partners via masking and remaining six feet apart. These findings suggest that for future endeavors aimed at reducing transmission, as in current campaigns to increase the uptake of COVID-19 vaccines, special attention should be paid to understanding and specifically targeting heterosexual men. Further, our findings indicate that gay and bisexual men are engaging in effective risk reduction strategies to keep an active, healthy sex life during the pandemic. It would greatly benefit public health researchers to pay particular attention to learning effective health promotion strategies from the gay and bisexual community, as our data and that of other researchers demonstrate that gay and bisexual people engage in active protection of their social networks. Extending this trend to heterosexual populations will be key in preventing the ongoing COVID-19 pandemic from escalating as the virus continues to mutate.

\section{Limitations}

Our findings should be taken in consideration with limitations. First, the data were collected online and therefore represent only those with access to the internet. Relatedly, the survey was largely promoted using social media, likely attracting a younger sample. Importantly, we did not specifically advertise the study as one focused on sexual behavior, and these data were not collected from Grindr or other dating apps, as has become common in research on men who have sex with men (Stephenson et al., 2020a, 2020b). Therefore, our sample may be more representative of overall gay and bisexual men's sexual activity patterns than in prior work sampling from an app linked to sexual activity. Future researchers may benefit from either online recruiting beyond social media, online probability sampling, or sampling via random digit dialing or mailing.

Second, the sample is predominantly White and highly educated. With a more racially and economically diverse sample, we may expect to observe greater variation in cognitions around COVID-19, as racial and ethnic minorities, those with lower education levels, and those with lower socioeconomic standing are more vulnerable to COVID-19 infection (; Hooper et al., 2020; Harkness et al., 2020; Hirko et al., 2020) and less likely to receive adequate care (Egede \& Walker, 2020; Li \& Galea, 2020). The sampling strategies recommended above should be considered by future researchers in this area in an effort to document these disparate cognitions and related needs.

Third, although we argue that gay and bisexual men are likely to have differing COVID-19 risk perceptions in relation to sex because of the HIV messaging they are likely to have been exposed to, we did not collect information on HIV status, testing, or risk perceptions. This voided our ability to analyze HIV cognitions in relation to COVID-19 risk perception formation or to compare the two across demographics. It also prohibited us from being able to demarcate groups of gay and bisexual men who may be more or less driven to act on behalf of their sexual health needs. While the present study documents existing disparities, future research should include these factors to identify intervenable factors to change COVID-19 cognitions and improve COVID-19 prevention behavior, particularly among groups that display low levels of prevention behavior, such as 
heterosexual men. If additional evidence is found that targeted health messaging and masculine norms for health behavior are responsible for these differences, interventions should be designed specifically to target heterosexual men that take these dynamics into account. We strongly encourage future researchers and interventionists to consider these factors in their research design.

Fourth, while we did collect data on participants' engagement in sexual behavior-specifically oral, anal, and vaginal sex-which could then be included in our models as covariates, we did not collect data on how often participants were engaging in the intimate but non-sexual behaviors (i.e., hugging, kissing). This renders our models a bit less accurate than the models that included actual engagement in the behavior as a covariate in cognitions about risk. This should be corrected in future research.

Relatedly, one weakness in our ability to fully understand risk perceptions and how they impact behavior is that we failed to collect data on participants' sexual behavior during the pandemic in comparison with their sexual behavior before the pandemic. Being able to pinpoint groups of participants who reported higher risk perceptions of intimate and sexual behaviors, and then also reported a lower rate of engagement during the pandemic compared to their more typical sexual lives, would be valuable as an identified "model" group. That is, these individuals would theoretically hold the cognitions that interventionists may wish to promote in others. Identifying these individuals and conducting more in-depth follow-up studies with them should be a goal of future researchers conducting studies in this area.

Finally, in our analyses, we grouped gay and bisexual men together rather than examining differences between the two identities. We did so due to the smaller sample size of bisexual men $(n=27)$ and because as men who have sex with men, gay and bisexual men are likely to have both been the target of HIV messaging campaigns that promote precautionary behavior and community protection. However, each of these sexual identities is unique and the lived experience of men with these identities may include a number of factors that would differentially impact their COVID-19 cognitions. Further research in this area should aim to capture perceptions without collapsing across target demographic groups.

\section{Conclusion}

In the USA, and around the globe, the COVID-19 pandemic will continue for the foreseeable future, with effects that the American people will likely feel for generations. The combination of disparate vaccination rates with rapidly developing variants of the COVID-19 virus point toward the need for highly efficacious, evidence-based COVID-19 behavioral interventions in the years to come. Critical behavioral change, from masking to current vaccination efforts, is needed on a countrywide level - an endeavor that needs interdisciplinary direction based on established empirical foundations. The literature from the fields of health psychology and public health have illustrated the importance of understanding how at-risk groups think about health threats, as these cognitions are strongly related to engagement in precautionary behavior (Ajzen, 1991). In our study, we found that sexual orientation may influence risk perceptions of COVID-19 transmission in the context of intimate and sexual interactions with others. This effect is potentially due to infectious disease messaging campaigns generally targeted at men who have sex with men. In the context of COVID-19, it is essential to better understand how people more at risk for infection perceive the threat and how these perceptions do or do not shape prevention behavior that can be identified for targeted intervention.

Acknowledgements We would also like to acknowledge Dr. [REDACTED FOR REVIEW] for funding this project with their [REDACTED FOR REVIEW] faculty funds and their support and guidance on this project.

\section{Declarations}

Conflict of interest The authors declare that they have no conflict of interest.

Ethical Approval All materials were approved by the IRB and each participant gave their informed consent.

\section{References}

Ajzen, I. (1991). The theory of planned behavior. Organizational Behavior and Human Decision Processes, 50(2), 179-211.

Ajzen, I., \& Madden, T. J. (1986). Prediction of goal-directed behavior: Attitudes, intentions, and perceived behavioral control. Journal of Experimental Social Psychology, 22(5), 453-474.

Andersen, M. (2020). Early evidence on social distancing in response to COVID-19 in the United States. Available at SSRN 3569368.

Bosman, J., Mervosh, S., \& Santora, M. (2020). As the Coronavirus Surges, a New Culprit Emerges: Pandemic Fatigue. New York Times.

Bowleg, L. (2004). Love, sex, and masculinity in sociocultural context: HIV concerns and condom use among African American men in heterosexual relationships. Men and Masculinities, 7(2), $166-186$.

Bowleg, L., Teti, M., Massie, J. S., Patel, A., Malebranche, D. J., \& Tschann, J. M. (2011). 'What does it take to be a man? What is a real man?': Ideologies of masculinity and HIV sexual risk among Black heterosexual men. Culture, Health \& Sexuality, 13(05), $545-559$.

Breslow, J. (2021, May 21). Dating Apps Are Making It Easier To Swipe Right For A Match Who's Vaccinated. NPR. https://www.npr.org/ 2021/05/21/999178100/single-dating-apps-are-making-it-easierto-swipe-right-for-a-match-whos-vaccinat.

Centers for Disease Control and Prevention, C.-R. (2021). COVID-19 Case Surveillance Public Data Access, Summary, and Limitations (version date: March 31, 2020). 
Centers for Disease Control and Prevention. (n.d.). Your Guide to Masks. Centers for Disease Control and Prevention. https://www. cdc.gov/coronavirus/2019-ncov/prevent-getting-sick/about-facecoverings.html.

Chang, S. J., Choi, S., Kim, S. A., \& Song, M. (2014). Intervention strategies based on information-motivation-behavioral skills model for health behavior change: A systematic review. Asian Nursing Research, 8(3), 172-181.

CNBC. (2020). Reopening America: A state-by-state breakdown of the status of coronavirus restrictions. Retrieved from https://www. cnbc.com/2020/04/30/coronavirus-states-lifting-stay-at-homeorders-reopening-businesses.html

Cucinotta, D., \& Vanelli, M. (2020). WHO declares COVID-19 a pandemic. Acta Bio-Medica: Atenei Parmensis, 91(1), 157-160.

Dalessandro, C. (2019). Dangerous sex: Gendered sexual bodies and perceptions of STI risk. Sexuality Research and Social Policy, 1, $1-11$.

Dryhurst, S., Schneider, C. R., Kerr, J., Freeman, A. L., Recchia, G., Van Der Bles, A. M., \& van der Linden, S. (2020). Risk perceptions of COVID-19 around the world. Journal of Risk Research, 1, 1-13.

Edwards, T. (2012). Erotics and politics: Gay male sexuality, masculinity and feminism: Routledge.

Egede, L. E., \& Walker, R. J. (2020). Structural racism, social risk factors, and Covid-19-a dangerous convergence for black Americans. New England Journal of Medicine, 383(12), 77.

Feng, S., Shen, C., Xia, N., Song, W., Fan, M., \& Cowling, B. J. (2020). Rational use of face masks in the COVID-19 pandemic. The Lancet Respiratory Medicine, 8(5), 434-436.

Ferrari, M., Speight, J., Beath, A., Browne, J. L., \& Mosely, K. (2021). The information-motivation-behavioral skills model explains physical activity levels for adults with type 2 diabetes across all weight classes. Psychology, Health \& Medicine, 26(3), 381-394.

Fisher, J. D., Fisher, W. A., Amico, K. R., \& Harman, J. J. (2006). An information-motivation-behavioral skills model of adherence to antiretroviral therapy. Health Psychology, 25(4), 462.

Fisher, J. D., \& Fisher, W. A. (2002). The information-motivationbehavioral skills model. Emerging Theories in Health Promotion Practice and Research: Strategies for Improving Public Health, 1, 40-70.

Fleming, P. J., Lee, J. G., \& Dworkin, S. L. (2014). "Real Men Don't": Constructions of masculinity and inadvertent harm in public health interventions. American Journal of Public Health, 104(6), $1029-1035$.

Gerhold, L. (2020). COVID-19: Risk perception and Coping strategies.

Grossman, G., Kim, S., Rexer, J., \& Thirumurthy, H. (2020). Political partisanship influences behavioral responses to governors' recommendations for COVID-19 prevention in the United States. Available at SSRN 3578695.

Harkness, A., Gattamorta, K. A., Estrada, Y., Jimenez, D., Kanamori, M., Prado, G., \& Behar-Zusman, V. (2020). Latinx health disparities research during COVID-19: Challenges and innovations. Annals of Behavioral Medicine, 54(8), 544-547.

Hirko, K. A., Kerver, J. M., Ford, S., Szafranski, C., Beckett, J., Kitchen, C., \& Wendling, A. L. (2020). Telehealth in response to the COVID-19 pandemic: Implications for rural health disparities. Journal of the American Medical Informatics Association, 27(11), 1816-1818.

Hooper, M. W., Nápoles, A. M., \& Pérez-Stable, E. J. (2020). COVID19 and racial/ethnic disparities. Jama.

Jacob, L., Smith, L., Butler, L., Barnett, Y., Grabovac, I., McDermott, D., Tully, M. A. (2020). COVID-19 social distancing and sexual activity in a sample of the British Public. The Journal of Sexual Medicine.

Jin, J.-M., Bai, P., He, W., Wu, F., Liu, X.-F., Han, D.-M., \& Yang, J.-K. (2020). Gender differences in patients with COVID-19:
Focus on severity and mortality. Frontiers in Public Health, 8,152 .

Kuzmina, A., Khalaila, Y., Voloshin, O., Keren-Naus, A., BoehmCohen, L., Raviv, Y., \& Taube, R. (2021). SARS-CoV-2 spike variants exhibit differential infectivity and neutralization resistance to convalescent or post-vaccination sera. Cell Host \& Microbe, 29(4), 522-528.

Lammers, J., Crusius, J., \& Gast, A. (2020). Correcting misperceptions of exponential coronavirus growth increases support for social distancing. Proceedings of the National Academy of Sciences, 117(28), 16264-16266.

Lehmiller, J. J., Garcia, J. R., Gesselman, A. N., \& Mark, K. P. (2020). Less sex, but more sexual diversity: changes in sexual behavior during the COVID-19 coronavirus pandemic. Leisure Sciences, $43,1-10$.

Levant, R. F., \& Wimer, D. J. (2014). Masculinity constructs as protective buffers and risk factors for men's health. American Journal of Men's Health, 8(2), 110-120.

Li, Y., \& Galea, S. (2020). Racism and the COVID-19 epidemic: Recommendations for health care workers. American Journal of Public Health, 110(7), 956-957.

Liddon, L., Kingerlee, R., \& Barry, J. A. (2018). Gender differences in preferences for psychological treatment, coping strategies, and triggers to help-seeking. British Journal of Clinical Psychology, 57(1), 42-58.

Lippke, S., \& Ziegelmann, J. P. (2008). Theory-based health behavior change: Developing, testing, and applying theories for evidencebased interventions. Applied Psychology, 57(4), 698-716.

Mallapaty, S. (2020). Why COVID outbreaks look set to worsen this winter. Nature, 586(7831), 653-653.

Nagoski, E. (2015). Come as you are: The surprising new science that will transform your sex life. Simon and Schuster.

Nathan, A. (2019). U = U Implementation in Rural North Carolina: Lessons Learned from Successful Health Promotion and Education Campaigns.

Pearce, K. (2020). What is social distancing and how can it slow the spread of COVID-19. The Hub.

Price, D. M., Fikslin, R. A., Goldberg, A. J., Gesselman, A. N., Loubriel, J. C., \& Brooks, J. (2020). Sexual orientation and differences in HIV cognitions. Personality and Individual Differences, $152,109531$.

Ravenhill, J. P., \& de Visser, R. O. (2017). “There are too many gay categories now": Discursive constructions of gay masculinity. Psychology of Men \& Masculinity, 18(4), 321.

Rosenstock, I. M. (1974). The health belief model and preventive health behavior. Health Education Monographs, 2(4), 354-386.

Sen-Crowe, B., McKenney, M., \& Elkbuli, A. (2020). Social distancing during the COVID-19 pandemic: Staying home save lives. The American Journal of Emergency Medicine. https://doi.org/ 10.1016/j.ajem.2020.03.063

Siegel, K., \& Meunier, É. (2019). Awareness and perceived effectiveness of HIV treatment as prevention among men who have sex with men in New York City. AIDS and Behavior, 23(7), 1974-1983.

Spagnolo, P. A., Manson, J. E., \& Joffe, H. (2020). Sex and gender differences in health: What the COVID-19 pandemic can teach us. In: American College of Physicians.

Stephenson, R., Chavanduka, T. M., Rosso, M. T., Sullivan, S. P., Pitter, R. A., Hunter, A. S., \& Rogers, E. (2020a). Contrasting the perceived severity of COVID-19 and HIV infection in an online survey of gay, bisexual, and other men who have sex with men during the US COVID-19 epidemic. American Journal of Men's Health, 14(5), 1557988320957545.

Stephenson, R., Chavanduka, T. M., Rosso, M. T., Sullivan, S. P., Pitter, R. A., Hunter, A. S., \& Rogers, E. (2020b). Sex in the time of COVID-19: Results of an online survey of gay, bisexual and other men who have sex with men's experience of sex and HIV 
prevention during the US COVID-19 epidemic. AIDS and Behavior, 25, 1-9.

Tabaac, A. R., Sutter, M. E., Wall, C. S., \& Baker, K. E. (2018). Gender identity disparities in cancer screening behaviors. American Journal of Preventive Medicine, 54(3), 385-393.

Teo, C. H., Ng, C. J., Booth, A., \& White, A. (2016). Barriers and facilitators to health screening in men: A systematic review. Social Science \& Medicine, 165, 168-176.

Veronese, V., Ryan, K. E., Hughes, C., Lim, M. S., Pedrana, A., \& Stoové, M. (2020). Using digital communication technology to increase HIV testing among men who have sex with men and transgender women: Systematic review and meta-analysis. Journal of Medical Internet Research, 22(7), 14230.

Walter, L. A., \& McGregor, A. J. (2020). Sex-and gender-specific observations and implications for COVID-19. Western Journal of Emergency Medicine, 21(3), 507.
Xin, M., Viswanath, K., Li, A.Y.-C., Wangnan, C., Yuhong, H., Lau, J.T.-F., \& Mo, P.K.-H. (2020). The effectiveness of electronic health interventions for promoting HIV-preventive behaviors among men who have sex with men: meta-analysis based on an integrative framework of design and implementation features. Journal of Medical Internet Research, 22(5), 15977.

Zarani, F., Besharat, M. A., Sadeghian, S., \& Sarami, G. (2010). The effectiveness of the information-motivation-behavioral skills model in promoting adherence in CABG patients. Journal of Health Psychology, 15(6), 828-837.

Publisher's Note Springer Nature remains neutral with regard to jurisdictional claims in published maps and institutional affiliations. 